\title{
Un modelo de análisis para la lectura comprensiva y la construcción de conocimientos culturales
}

\author{
A Model of Analysis for Comprehensive Reading \\ and the Construction of Cultural Knowledge \\ Um modelo de análise para a leitura compreensiva \\ e a construção de conhecimentos culturais
}

Eder García Dussan ${ }^{1}$

\section{Resumen}

El artículo comprende las circunstancias pedagógicas y didácticas desplegadas en una práctica de formación de profesores, en el contexto de un espacio académico cuyo interés era fortalecer habilidades de lectura comprensiva, a propósito del texto audiovisual Une liaison pornographique, del director belga Frédéric Fonteyne (1999). El desarrollo estuvo orientado por premisas teóricas y metódicas propias de la perspectiva sociosemiótica, las cuales generaron un plus en esta experiencia colectiva, dejando ver cómo la lectura intertextualparatextual es derivación de la puesta en escena de espacios dialógicos donde se explicitan saberes enciclopédicos que expresan libre pero metódicamente acervos textuales de los participantes. Los resultados de tal rutina permitieron concluir que la formación de lectores no solo está atravesada por la afectación subjetiva, sino que esta sirve de pivote para el progreso de lecturas inferenciales intersubjetivas y democráticas, paso inicial para la construcción de conocimientos explícitos de tipo cultural.

Palabras clave: Conocimiento explícito, conocimiento cultural, investigación reflexiva, texto cinematográfico, lector intérprete, traducción.

\section{Abstract}

This article summarizes the pedagogical and didactic circumstances that are dispersed out in a practice of training teachers, in setting of an academic space with the interest was to strengthen weak reading comprehension skills, taking into account the audiovisual text, Une liaison pornographique by the Belgian director Frederic Fonteyne (1999). The development of this experience was derived from theorical and methodic premises of the social- semiotic perspective, illustrating to us how intertextual-paratextual reading is a consequence of the setting in scene of dialogic spaces where encyclopedic knowledge is shown and expressed freely and methodically textual stock from participants. The results of this experience allow us to conclude that the training of readers is not only intersected by the subjective involvement, but also it serves as a pivot for the advancement of democratic, intersubjective and inferential readings as an initial step for the construction of explicit cultural knowledge.

Keywords: Explicit knowledge, cultural knowledge, reflective research, screenplay, interpreter reader, translation.

\section{Resumo}

0 artigo compreendia as circunstâncias pedagógicas e didáticas desenvolvidas numa prática de formação de professores, no contexto de um espaço acadêmico, cujo interesse era fortalecer habilidades de leitura compreensiva, a propósito do texto audiovisual Une liaison pornographique, do diretor belga Frédéric Fonteyne (1999). 0 desenvolvimento esteve orientado por premissas teóricas e metódicas próprias da perspectiva sociosemiótica, as quais geraram uma extra nesta experiência coletiva, deixando ver como a leitura intertextual-paratextual é derivação da posta em cena de espaços dialógicos, onde explicitam-se saberes enciclopédicos que expressam livre, mas metodicamente acervos textuais dos participantes. Os resultados dessa rotina permitiram concluir que a formação de leitores, não só está atravessada pela afetação subjetiva, mas que serve de articulação para o progresso de leituras inferenciais, intersubjetivas e democráticas, passo inicial para a construção de conhecimentos explícitos de tipo cultural.

Palavras-chave: Conhecimento explícito, conhecimento cultural, pesquisa reflexiva, texto cinematográfico, leitor interprete.

Artículo recibido el 26 de abril de 2015 y aprobado el 26 de junio de 2015

1 Universidad Distrital Francisco José de Caldas, Bogotá, Colombia. Correo electrónico: eagarciad@udistrital.edu.co 
Habitualmente se está en procura de progresos frente a los procesos de lectoescritura, lo cual cobra una importancia radical cuando se hacen públicas estadísticas que indican la deficiencia de estos en la escuela básica e, incluso, en la universidad, tal como ha sucedido últimamente con los resultados en las pruebas Pisa de los estudiantes colombianos y su confirmación con estudios locales ( $v . g r$. Linares, 2013; Cajiao, 2014). A partir de este panorama, comienzan a determinarse focos causales de la situación sobre el escenario escolar general, y la pedagogía de la lectura, en particular. Básicamente, y sin mucho esfuerzo, se puede imputar la actualidad del asunto al sistema educativo, a los estudiantes, a los profesores o a todos de un solo golpe. No obstante, si se parte de la apuesta que toda fractura en el contrato escolar es, en parte, causada por la ausencia de la cualificación del docente, es conveniente que sean los profesores, y no los investigadores, quienes expresen las falencias personales, pero también los problemas, las reflexiones y las soluciones.

De aceptarse esto, tal determinación nos ubica en el campo de la investigación pedagógica, entendida como una reflexión-acción agenciada por los maestros, quienes, tras sospechar de su quehacer, toman distancia de él y lo interrogan a partir de cuestiones como qué se enseña, cómo, a quién, con qué medios y en qué contextos, lo cual forma un saber pedagógico (Camargo, 2005). Dentro de esos esfuerzos por generar investigación pedagógica, la Maestría en Pedagogía de la Lengua Materna (MPLM), de la Universidad Distrital Francisco José de Caldas (Bogotá), oferta una estructura curricular que se organiza a partir de tres campos de formación (lingüístico discursivo, pedagógico, didáctico e investigativo y electivo), los cuales se integran progresivamente para permitir la investigación sobre el lenguaje como práctica social, con el fin de profundizar en los procesos de enseñanza y aprendizaje, y también en los fundamentos para la adquisición y producción de conocimientos, competencias y habilidades relacionadas con las modalidades oral (habla, escucha), escrita (lectura, escritura) y estética (literatura, arte des-regulado) de la lengua materna.
Ahora bien, para que esta estructura curricular sea posible, creemos que es necesario contar con unos docentes que puedan implementar la investigación en sus propias prácticas pedagógicas cotidianas (Mejía, 2009). Para lograr esto, las acciones internas de la MPLM tienden a privilegiar una ruta general que se desglosa en una escalonada forma de planear, ejecutar y valorar problemáticas y cuyas actividades apuestan por la democratización de las actividades en el aula, la construcción asistida de saberes y la consolidación de metodologías que efectúen el reconocimiento social de los actores, quienes ponen en juego las diferentes concepciones y representaciones a través de la negociación cultural de sus expectativas. El fin de todo este esfuerzo es que lo hecho así y allí sirva de molde para transferencias en escenarios que apuntan a la transformación de las condiciones de control, dominio y formas de sujeción de los actores escolares en las comunidades letradas. En este orden de ideas:

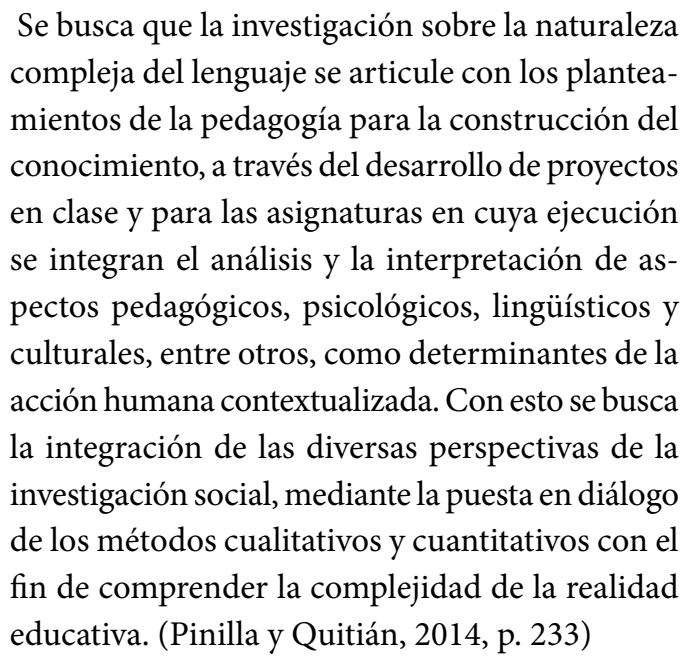

Ahora, una de esas "perspectivas de investigación social" por la que apuesta la MPLM es la que Donald Schön llamó "la investigación reflexiva" (1998). Para este pensador estadounidense resulta con frecuencia muy complicado que alguien comunique lo que conoce; de hecho, el conocimiento parece reposar como un stock de esquemas implícitos que se hace patente en los escenarios de la inter-acción, tal como suele suceder en el ambiente escolar cuando un profesor propone socializar un corpus de información para dilatarlo o transponerlo pero, sobre todo, 
para inferir de él nuevos conocimientos a partir de unas pesquisas y digresiones, a veces leídos como actos mágicos en los estudiantes. No obstante, lo que actualiza un profesor al dar cuenta de un orden discursivo determinado es el resultado de una labor previa que ha construido al asociar experiencias propias, investigaciones intertextuales ovilladas con cierta madurez temporal y asimilación de las experiencias de otros sobre el área temática de despliegan esos textos, excusa de la interacción. Luego, una vez organizado todo esto, los comunica a sus pupilos en espacios que permitan dinamizar la reflexión de su experiencia, con el fin de que se generen y actualicen nuevos conocimientos y habilidades.

Pues bien, muchos de esos conocimientos explicitados en el aula, y que sobreviven en un ciclo que va de lo individual a lo grupal y de lo tácito a lo explícito, corresponden a conocimientos socioculturales, con los cuales cualquier sujeto afecta su consciencia y, de este modo amplía y desarrolla sus cosmovisiones, y alimenta, así, una formación integral (Bildungswissen), la que le permite una reconfiguración de su ser, y no solo una instrucción y una información descontextualizadas.

Aprovechando esto, creemos que un medio regio para contribuir a este tipo de formación y, concretamente a la formación de lectores más expertos o menos ingenuos, se logra por medio de las premisas básicas que describe Schön para adelantar soluciones a través del conocimiento procedimental (1998): la descripción y el análisis de ciertos casos y sumarios culturales que permiten la generación de hipótesis de sentido sobre su funcionamiento e intencionalidad; lo cual logran los sujetos tras la manipulación de esos casos texturales, y que terminan aportando a la ganancia de nuevos conocimientos. Así, pues, para Schön, se trata de adelantar una secuencia de acciones surgida a partir de un problema (manual o intelectual), el cual dispara la búsqueda de estrategias concretas a partir de pistas y claves que auxilian la solución (teoría, modelo, didáctica), todo para llegar a una meta (habilidad, tarea resuelta, comprensión crítica), de la misma manera como sucede cuando se aprende a conducir un coche. Solo que para esto, el sujeto comprometido debe planificar, observar sus acciones, es decir, autorregularse y contralar la toma de decisiones que le permiten llegar al a meta.

En nuestro caso, esta apuesta de la investigaciónreflexión-acción se concretó en varias ocasiones a propósito de las actividades grupales guiadas por el responsable de un seminario temático sobre semiología del cine, realizado en el primer semestre de 2014 en el seno de una Maestría en Pedagogía de la Lengua Materna, con un colectivo de casi dos decenas de maestrantes interesados en cualificar sus prácticas sobre lectura de textos multimodales. Pues bien, al tomar como disculpa los textos cinematográficos, y siguiendo una práctica de lectura que presta atención a los detalles indiciales presentes en el la red de elementos narrativos constitutivos de todo filme, se adelantó una sesión que evidenció la manera en que la estrategia de la descripción y análisis colectivo de este tipo de productos culturales se convirtió en un ejemplo de cómo la práctica se hace reflexión y de cómo la ganancia de conocimientos, tanto estratégicos como culturales, fueron efectos del apoyo sobre algunos elementos teoréticos y didácticos de base.

Así, pues, para lograr un trazado justo de tal experiencia de producción de saberes explícitos en esa práctica grupal, en un primer momento daremos cuenta de algunos referentes teóricos básicos que motivaron el seminario en cuestión, dado que, si bien es cierto, la formación de los docentes-lectores debe incidir en sus prácticas desde el inicio, puesto que la práctica es lo fundamental, la teoría actuó como herramienta para el diseño de métodos, pero también para el análisis y la revisión de las nuevas prácticas. En seguida, describiremos brevemente el modelo de lectura indicial usado en las actividades de comprensión lectora para la intervención con textos cinematográficos y, finalmente, puntualizaremos el ejemplo más significativo que se logró en esa experiencia, que fue con el filme Une liaison pornographique (An affaire of love, Una relación intima), de Fonteyne (1999), evento que nos llevó a una actividad de lectura crítica suscitada por la 
inclusión de dos nuevos productos simbólicos (dos cuentos breves de autores latinoamericanos), los cuales, siendo de la misma naturaleza tipológica que el texto de base, permitieron el tránsito hacia un enriquecimiento de conocimientos. Todo esto nos permitirá rematar al final del trazado pormenorizado de la experiencia en dos sentidos, a saber: uno epistemológico y otro metódico.

\section{La lectura de textos desde la perspectiva sociosemiótica}

Charles Sarland (2003) sostiene que la lectura no es un acto que exija ciertas habilidades mecánicas, sino un proceso donde hay una significativa ganancia de conocimientos y expectativas sobre el mundo textual cuando se crean los contextos en los que la lectura encuentra sentido. Por esa línea, la perspectiva semiótica frente al acto lector hace énfasis en el lector Entdeckerin (descifrador), y no tanto en el autor ni en el texto, pasando de esta manera de la trans-acción, propia de posturas cognitivistas, a la co-participación y la asistencia. Umberto Eco (1981) enseña que la lectura es un proceso en el que el lector coopera con el texto, proporcionándole una interpretación; solo que para llegar a esa interpretación se vale de su competencia circunstancial y su enciclopedia, fundamentos por medio de los cuales actualiza el contenido del texto que lee; es decir, completa los espacios en blanco que encuentra mientras lee (Leerstellen), el cual está plagado de elementos no dichos en la superficie, además de espacios de indeterminación (Unbestimmtheit) que exigen ser actualizados para llegar al sentido. Así las cosas, este proceso de reajuste beneficia al lector, contribuyendo con la formación de su competencia y haciéndolo partícipe de la obra. Eco lo resume así: "[...] un texto, tal como aparece en su superficie o manifestación lingüística, representa una cadena de artificios expresivos que el destinatario debe actualizar" (1981, p. 71).

Estos son los fundamentos cardinales del modelo del lector intérprete, en el que este tiene sobre sí la función de reconocer y rellenar/saturar los huecos o espacios blancos que el texto va develando al ser atravesado por la pericia de quien lo actualiza. Esta reflexión-acción dispara dos factores, a saber: (I) el factor económico, que domina las manifestaciones lingüísticas, pues no hace falta que detallemos en exceso cuando componemos textos, pues el autor intenta compaginar competencias lingüísticas y enciclopédicas mínimas para anticipar los movimientos del potencial lector de su producto; $y$, (II) el factor estético, en virtud del cual el texto está concebido para dejar al lector la iniciativa de interpretarlo y que su comprensión, meta del acto mismo, le procure deleite o placer a través del aprecio de los usos creativos del lenguaje, manifestados en hipótesis de sentido sobre el querer-decir de la obra.

Este modelo está acreditado también por el teórico polaco Roman Ingarden (1998), quien afirma que la obra es un conjunto de "perspectivas esquemáticas", direcciones generales que el lector debe actualizar cuando lee hacia atrás y hacia delante, de arriba a abajo, y viceversa; y es gracias a esos movimientos como va aportando información exterior que se gobierna desde el afuera del texto hacia los fondos textuales, dando así sentido a los primeros planos, acciones que le permitirán intervenir la profundidad del texto.

Ahora, para no caer en especulaciones y alucinaciones interpretativas, es necesario ser audaz a la hora de jugar con el fondo y la figura de los textos, lo cual se visibiliza cuando el lector analiza cada unidad textual y se da cuenta de que es susceptible de ser relacionada con el contexto histórico y sociocultural, desde una traza diacrónica y/o sincrónica. Esto, muchas veces, está fijado en un lexema que actúa como indicio y se disfraza de tropo o metasema, acciones muy frecuentes en el nivel léxico-semántico; pero también, si pensamos en los textos cinematográficos, en expresiones, imágenes, silencios o relatos sugestivos, voces en off surgidas en momentos clave de ciertos programas narrativos, juegos cromáticos, etc. Aquí se ve, entonces, la necesidad urgente de pasar de lo literal a la organización inferencial-indicial. Esta fase debe canalizar de manera orgánica el conocimiento producido en todo el proceso lector, para lo cual es 
necesario guiarse de datos contextuales y de la cual dice Beristáin que "[...] se trata de una nueva lectura que busca las múltiples relaciones dadas entre las unidades y los variados elementos de naturaleza literaria, pictórica, arquitectónica, en fin, artística" (1997, p. 123).

\section{Pistas para la enseñanza de la lectura comprensiva}

En diversas ocasiones hemos insistido en un modelo pensado no solo para la formación de estudiantes expertos en capacidades lectoescritoras, sino de lectores no ingenuos (leedores y no lectores), que tomen todas las texturas culturales y transformen sus tesoros de significación sociocultural a través de la generación de hipótesis explicativas de hechos textuales. Este modelo citado se propone guiar un acto lector a través de la ubicación de pistas textuales que actúan como signos-indicios. Para lograr esta meta, se tienen en cuenta, al menos, siete elementos determinantes, que a continuación resumimos:

1. La premisa indispensable para la formación de leedores está centrada en el fortalecimiento de habilidades metalingüísticas, puesto que el desarrollo de competencias influye en los procesos de lectoescritura, especialmente en la decodificación textual (Flórez et al., 2005).

2. Mientras se lee para comprender, hay una actualización de cuatro principios de acción: (I) Todo texto, con lo que dice, quiere decir algo más (el discurso se presenta como un iceberg; así, todo producto cultural se concibe en su doble naturaleza funcional); (II) nadie enuncia nada desde la nada (el texto deviene discurso: está inscrito en coordenadas físicas, sociohistóricas, sociopolíticas, culturales y cognitivas); (III) pese al principio anterior, el discurso no se limita a las determinaciones contextuales (todo discurso es una obra abierta y atemporal, que captura, incluso, al propio lector, que nunca es el mismo en ninguna época); y (IV) el leedor es coautor del discurso (el leedor llena vacíos, con-forma, re-configura y completa y/o actualiza los con- tenidos del texto con sus propios "horizontes de sentido").

3. Los procesos cognitivos y las estrategias que se llevan a cabo mientras se lee, se pueden resumir en dos grandes etapas (en ellos, el leedor activa siempre unos conocimientos o saberes previos): (I) una etapa de análisis o de tensión, que forja una labor intratextual en la que se separan los diferentes componentes del texto y se examinan las propiedades y funciones en algunos niveles lingüísticos ( $v . g r$. el léxico-semántico, el pragmático, etc.), para buscar material indexical; y (II) una etapa de interpretación, hermenéutica o de distensión, que genera un trabajo extra e intertextual, en el que se manipula la arquitectura indicial y se crean relaciones hasta lograr hipótesis de sentido sobre el querer decir del texto.

4. Sin análisis no hay interpretación; y sin estas, en ese orden, no hay comprensión: [Análisis + Interpretación $=$ Comprensión $]$.

5. El análisis es una operación que separa cuatro componentes presentes en todo texto, a saber: (I) la referencialidad o narratividad (¿qué dice?, ¿cómo lo dice?); (II) la actancialidad o estudio de los roles (perfiles psicológicos, acciones y posiciones dentro del relato); (III) la cronotopía (¿dónde?, ¿cuándo?); y (Iv) la indexicalidad (¿qué elementos o huellas textuales permiten asociar implicaturas socioculturales: sobreentendidos, presupuestos, informaciones históricas?).

6. La interpretación es una operación que reduce el acto lector a un arte de la investigación y que permite avanzar una traducción. Es que la formación lectora asumida como experiencia vital implica transformaciones. Según Larrosa (2007), leer se puede definir como un acto de traducción que genera resignificación de significantes en la lógica metafórica del lector como traductor.

7. La comprensión se manifiesta en, mínimo, la presentación de una hipótesis de sentido. 
Pues bien, una vez socializado este modelo al grupo del Seminario, sirvió como una "estrella de Belén" que orientó la acción colectiva cuya meta fue la construcción de, al menos, una hipótesis de sentido sobre cada producto manipulado. En esa medida, cualquier noción o apuesta que aparecía podía ser justificada gracias a alguno de los axiomas del modelo aquí resumido, lo cual permitió la convivencia de ideas con la sensación de no estar trabajando ilusoriamente, sino evitando el surgimiento de esa nueva sensibilidad del "allí todo vale" (everything goes), del todo es posible.

\section{Sobre la experiencia colectiva con el filme Une liaison pornographique}

Bien, tras ver en el aula de clase el filme Une liaison pornographique, la experiencia lectora siguió con la determinación de un problema orientador y propedéutico que ciframos así: "Qué tanto de pornográfico se revela en la película” y, desde allí, “¿cuál es la verdadera intención de la historia pornográfica allí instaurada?". Esta pregunta, que gobernó el proceso de acciones previas a la lectura analítica, sirvió de problema orientador al trabajo descifrador.

El acto seguido, de acuerdo con el modelo de Schön, fue determinar nuestro conjunto de estrategias para avanzar en nuestro propósito, las cuales se agenciaron desde las premisas del modelo lector propuesto arriba, aquel inspirado en premisas sociosemióticas. En este, el profesor responsable del curso electivo fue una guía que impidió que se distorsionara el esfuerzo con opiniones o acciones fuera de los marcos pedagógico y didáctico acuñados, con base en una planificación que el mismo modelo orienta, a saber: momento de análisis, momento de interpretación y determinación del(os) sentido(s), manifestado a través de una hipótesis sobre su querer decir, meta explícita de todo el proceso. Claramente, en todo esto, el profesor también debía estar vigilante de los desvíos y promover, cuando ellos afloraran, una "reflexión en la acción" una conversación reflexiva entre los participantes y los elementos de la situación (Cassís, 2011). Notorio es, entonces, cómo se evidenció la orientación propuesta por Schön en el ejercicio lector de la película francesa, cuyos detalles de desglosan a continuación.

Lo primero que se adelantó en conjunto fue la reconstrucción o transliteración de los programas narrativos (PN) que nos permitieran la manipulación del texto cinematográfico. Profesor y maestrantes concebimos once PN que incluían una orientación, unas secuencias con evaluaciones intercaladas y una resolución. Estos PN detallaron los ocho encuentros que representó la trama base de la cinta, a saber: una pareja en su aventura amorosa, tras conocerse por medio de un anuncio en una revista pornográfica, y cuya reconstrucción se hace con un recuento, a cámara y por separado en entrevistas, frente a un aparente psicólogo o juez. Este fue el primer paso que, se advirtió muchas veces, consentiría la ubicación del material indicial presente de manera velada en la película. El resultado se muestra en la tabla 1.

Posteriormente, nos detuvimos a observar las acciones encaminadas a buscar indicios textuales, descubrimos un desliz procedimental frecuente: si bien es cierto que sospechábamos que cada PN escondía un significado secreto, muchas cosas de las dichas en la marcha al respecto del texto no estaban apoyadas en el juego texto-contexto a partir de los hechos que elegíamos como indicios; de esta suerte caíamos en el fenómeno de sobre-interpretación, al decir de Eco (1995). Esto nos obligó a planificar otra vez las acciones, por lo que decidimos emplear una nueva, a partir de la concientización del error del primer intento. Fue así como se hacía evidente la necesidad de conversar reflexivamente con nuestros propios actos de lectura con el fin de lograr la meta. Acudimos, así, a una "reflexión en la acción" (Schön, 1996), puesto que nos deteníamos a pensar en cómo es que estábamos comportándonos frente a nuestro objetivo problémico. De esta manera se dieron las posibilidades de modificar los resultados para optimizar la futura hipótesis de sentido que nos permitiría comprender el sentido oculto presente en el filme. La decisión fue, en adelante, no especular, no salirnos de lo que los indicios textuales nos ofrecían. Se estableció, entonces, una conversación reflexiva entre nosotros y los elementos sintáctico-semánticos de la película, que actuaba, en general, como una situación (Schön, 1998). 
Tabla 1. Reconstrucción del filme Une liaison pornographique a través de secuencias narrativas

\begin{tabular}{|l|l|}
\hline \multicolumn{1}{c|}{$\begin{array}{c}\text { Tiempo } \\
\text { (min) }\end{array}$} & \multicolumn{1}{c|}{ Frame } \\
\hline $2-6$ & Frente a un confidente \\
\hline & $\begin{array}{l}\text { Primer encuentro, en un } \\
\text { café }\end{array}$ \\
\hline $7-16$ &
\end{tabular}

Una mujer de pelo corto afirma: "Nuestra relación era una forma especial de sexo. Era una fantasía que necesitaba realizar para liberarme de ella; pero todavía la tengo". Un hombre con barba muestra la revista, bien conservada, donde reposa el anuncio con el que se conocieron, y afirma: "Soy un gran romántico".

La mujer, francesa, un poco frenética, referencia encuentros previos con hombres donde se sentía engañada, decepcionada. Toma la iniciativa e invita al hombre al hotel quien, más controlado, acepta ir con ella.

\section{En el hotel

Segundo encuentro, en el
hotel

$17-23$

Frente al confesor
24-25 Tercer encuentro, en un restaurante

Cuarto encuentro, en el café

26-36

En el hotel

\begin{tabular}{|l|l|}
\hline $37-38$ & Fuera del hotel \\
\hline $39-42$ & Quinto encuentro \\
\hline
\end{tabular}

43-48 Sexto Encuentro

49-53 Hospital Salpêtrière

54-65 Séptimo encuentro

Encuentro final, en el café

66-74 En el hotel

Ella frente al confesor
No se ve lo que hacen en la habitación. Solo se muestra el pasillo del hotel. Se sabe que fue valorado positivamente por él y ella. No confiesan la fantasía hecha al confidente.

Igualmente, no se ve nada de sus acciones dentro de la habitación. Al salir, él la invita a un restaurante en la noche; ella accede (voz en off: "Esas frases desencadenaron todo, pero en ese momento no me di cuenta"). Una vez allí, platican y deciden volver al hotel. Al salir, él le ayuda a tomar un taxi. Cuando se despiden ella le dice que hubiera convenido una persona con la que solo hubiera sexo. Él le pregunta si eso es lo que quiere, y ella le responde negativamente.

Ella afirma: "Fuera de la habitación no deberíamos haber cruzado una palabra, pero quedamos esa noche [...] era la primera vez que me encontraba tan relajada con un hombre. Con los demás siempre había malentendidos, pero con él no. Simplemente hablamos".

Ella le cuenta a él la "leyenda de Kabylie".

Ella le dice: "¿Y si hacemos el amor de forma normal? [...] no me gusta estar debajo. Me gusta dominar" (voz en off: "Es extraño tener un hombre al frente y sentir que te desea y que al mismo tiempo tú lo deseas". Él acepta (voz en off: "Estaba pasando algo más; me estaba acostumbrando a ella").

Por primera vez, el espectador ve en interior de la habitación, de fondo azul. Están en la cama, entre sábanas blancas. Comienza el acto sexual, ella encima de él, lleva el dominio y habla; él trata de evadirse emocionalmente para preservar el deseo de ella. Imagen de ellos entre las sábanas (voz en off de ella: "Fue la primera vez que tuvimos un orgasmo simultáneo. Con él fue perfecto"). Mientras caminan en una calle parisina, ella rompe en llanto (voz en off: "No sabía por qué lloraba. Estaba triste. Estaba perdida. De repente no sabía qué sentir").

En el café traban una discusión conflictiva. Cuando salen del hotel, dejan abierta la posibilidad de encontrarse o no la semana siguiente. Tras despedirse, él se altera y la sigue por el metro sin lograr alcanzarla.

Una vez se encuentran en el café, parten al hotel, donde apresuradamente se acarician con pasión. Los interrumpe un anciano quien se equivoca de habitación (la 118 por la 115). Unos segundos después el viejo se desploma en el pasillo. Lo auxilian y el viejo ruega que no llamen a su esposa, pues argumenta que no la soporta. Luego se quita el anillo y lo guarda.

Encuentro de la pareja con la señora Lignaux. Ella les manifiesta que su esposo siempre fue infiel, pero que ella nunca se lo reprochó porque él regresaba a su lado. Pero como ahora "[...] se va para no volver, no podré soportarlo. Espero que algún día lo entiendan porque sacrificas la vida por el otro y cuando ese otro se va, no te queda nada. Lo único que puedes hacer es suicidarte". (Voz en off de ella: "Fue el único acontecimiento exterior de nuestra historia. Lo único que sucedió sin que lo hayamos decidido, ni él ni yo [...] yo sentí que aquello no era casualidad, significaba algo, quería decir algo").

En el café ella le cuenta que la Sra. Lignaux se ha suicidado. Posteriormente, le declara su amor. Él llora de emoción. Deciden ir al hotel y platican y juguetean amorosamente en la tina del baño. Una vez en la cama, ella pregunta: “Qué nos pasará?" Deciden meditarlo hasta el otro encuentro. Vestidos de negro. Él toma la iniciativa y habla por los dos: "Lo nuestro no funcionará" (voz en off, se sabe que cada uno había resuelto quedarse y aportar una relación duradera). Deciden intimar una última vez.

Se ve el pasillo, fondo rojo. Voz en off de él: "Terminamos como habíamos empezado. Realizamos nuestra fantasía por última vez" (el espectador nunca sabe cuál era esa fantasía).

Confiesa que después de la última cita, lo vio en un parque local parquear su coche. Lo interesante es que lo ve a través de una pila de agua que fluye de arriba hacia abajo. La última escena la muestra con cara de fiasco. 
Una vez reencausada nuestra labor, lejanos ya de lecturas superficiales de la cinta, encontramos una clave sustancial entre sus finos hilos textuales: tras su tercer encuentro íntimo en el hotel, él y ella decidieron ir a dialogar en un restaurante. Entonces, la mujer le habla de la "leyenda de Kabylie", según ella, la certera historia de Adán y Eva:

Cuando se conocieron Adán y Eva, estaban desnudos y habían llegado a un mundo cubierto de nieve. Eva estaba caminando en la nieve y se tropezó con Adán. Ella se asustó y empezó a retroceder y se cayó de espaldas. Su espalda se enfrió y Adán empezó a frotarla; entonces se excitó y le hizo el primer niño. ( $\min 24-25)$

Este PN resultó muy llamativo para todo el grupo por la referencia a una supuesta leyenda con nombre propio; por lo cual quedó enlistado como material indicial. Esto estaba previsto en la planificación del profesor y emergió naturalmente dentro del proceso colaborativo. Fue así como, dándole relieve sustancial a esto último, nos permitimos unirlo con eventos presentados en la cuarta cita vivida por él y ella, en la cual ella propone hacer el amor, normalmente. De inmediato, se jugó con nuestra morbosidad como espectadores: ¿qué era, entonces, lo que hacían en los primeros encuentros?

El desarrollo de esto, en un ambiente azul que simbolizamos como de confianza y comunicación armónica, muestra los pormenores del comercio carnal de la pareja: entre sábanas blancas, comienza el acto sexual, ella lleva el dominio (se sitúa arriba del hombre y habla). Aún más, ella misma había dicho previamente: "No me gusta estar debajo. Me gusta dominar". Posteriormente, se cubren con las sábanas y construyen así una perfecta imagen de huevo, que podemos simbolizar como el origen, el paraíso y, de paso, genera el intertexto de la primera pareja de humanos, según la leyenda griega. La escena se consume con la imagen de ellos entre las sábanas. Al final una voz en off de ella: "Fue la primera vez que tuvimos un orgasmo simultáneo. Con él fue perfecto" ( $\min 26-36$ ).

Ahora, después de consumado el comercio carnal, salen por las calles parisinas; entonces ella llora y huye apresurada. La voz en off alerta: "Estaba perdida. De repente no sabía qué sentir" (min 37-38). Este PN fue tomado como complemento del material indicial previo, dado que los refuerzos informativos de las voces en off fueron considerados guías interpretativos de la historia velada que desarrollaba el filme.

El desenlace de la historia revela la rotura de la relación (min 66-74): él decide por los dos que no formalicen su íntima relación, y lo único que podemos saber es lo que afirma la mujer en el clímax del filme: lo importante era que realizaban verdaderos actos de amor, de lo cual solo quedan imágenes insinuantes al respecto. Por ejemplo, la imagen que muestra la satisfacción de la pareja: juntos, en la tina del baño del mismo cuarto de hotel, jugando con el agua, entre un fondo rojo y azul. Escena que se relaciona con el final de la cinta, pues cuando ella vuelve a verlo, lo hace a través de una fuente de agua que hace oscilar el líquido.

Lo significativo de esto fue que un análisis consensuado nos permitió entender, espacio-temporalmente, la presentación de una historia entre un él y una ella en Paris (Francia) ${ }^{2}$, que despuntaba en el siglo XXI, y cuya cualificación en el filme se comportó a lo largo de la historia como una pérdida progresiva del poder anclado en la figura femenina, y concedido al hombre (tabla 2).

Con ese conjunto de datos indexicales, activamos unas brigadas de indagación contextual, cristalizando de esta forma la "investigación reflexiva" centrada en dos eventos textuales clave, a saber: "Leyenda de Kabylie" y la afirmación de ella "no me gusta estar debajo. Me gusta dominar". Tras una discusión de datos hallados en red, esto es, explorando en la misma aula de clase por el buscador Google, gracias a los equipos audiovisuales allí situados, se llegó al significante Eva. En ese momento, sabíamos que habíamos trascendido el nivel literal del texto en cuestión. Como se sabe, en la mitología hebrea, Eva

2 La confirmación de la ciudad se dio cuando se investigó por la existencia y ubicación del hospital La Salpêtrière, citado en la cinta. Efectivamente, esta es una célebre institución médica parisina; de hecho, es uno de los hospitales más grandes de Europa. 
es la segunda mujer de Adán; la primera es Lilith, solo que por decisiones de censura por parte de los primeros padres del cristianismo, la figura de Lilith está elidida de las versiones bíblicas que conocemos. Entre otras informaciones traídas a la discusión, aparecieron datos como que Lilith y Adán fueron creados por Dios, pero, Lilith no ajustó como compañía para Adán porque este le pidió, en el comercio carnal, estar arriba; a lo que Lilith se negó afirmando que habían sido creados iguales ${ }^{3} y$ entonces debían hacer el amor en posiciones iguales; es decir, la postura recostada que él exigía era ofensiva para ella. Según el mito, revelado por el antropólogo judío Robert Graves (2000), Lilith fue con Yahweh, conoció su nombre sagrado, lo pronunció y voló lejos del Jardín del Edén y, por tanto, de Adán para siempre; se convirtió, luego, en la esposa de Asmodeus, el rey de los demonios, y desovó muchos miles de niños-demonio.

Tabla 2. Detalles actanciales en el desarrollo de la historia

\begin{tabular}{|c|c|c|}
\hline & Ella & Él \\
\hline Estado inicial & $\begin{array}{l}\text { Resuelta, impetuosa, vehemente, independiente, habla de sus ex- } \\
\text { periencias amatorias previas sin recato, hace el alquiler del hotelito } \\
\text { Deseo[+ poder, + saber, + deber] }\end{array}$ & $\begin{array}{l}\text { Es el "romántico" y cuidadoso con los objetos- } \\
\text { recuerdo (sensible, detallista) } \\
\text { Deseo[- poder, - saber, - deber] }\end{array}$ \\
\hline Estado medial & $\begin{array}{l}\text { Habla de sus relaciones amatorias previas, evoca leyendas para } \\
\text { promulgar su poder, propone cómo adelantar los encuentros ínti- } \\
\text { mos, está encima de él en las relaciones sexuales "normales"; no } \\
\text { obstante, llora solitaria y sin razón aparente y se pregunta por su } \\
\text { destino } \\
\text { Deseo[+ poder, + saber, + deber] }\end{array}$ & $\begin{array}{l}\text { Acepta sin resistencia las proposiciones de ella, es } \\
\text { amable, es quien se angustia por no volverla a ver } \\
\text { (corre desmedido por el metro), guarda un anillo } \\
\text { (señales), llora de emoción frente a las acciones } \\
\text { de ella... } \\
\text { Deseo[- poder, - saber, - deber] }\end{array}$ \\
\hline Estado final & $\begin{array}{l}\text { En el momento de decidir el destino de la relación, acepta la deci- } \\
\text { sión de él; posteriormente lo ve, pero derrotada, no decide abor- } \\
\text { darlo } \\
\text { + Deseo, - poder, - saber, + deber }\end{array}$ & $\begin{array}{l}\text { Decide por los dos, en contra de su deseo y desco- } \\
\text { nociendo el deseo de ella } \\
\text { + poder, + saber, + deber (¿deseo?) }\end{array}$ \\
\hline
\end{tabular}

Tras la captura de ese conocimiento cultural que, por cierto, dejó sorprendidos a muchos de los asistentes, las asociaciones logradas se ajustaron a propósito de algunos hechos textual-indexicales del filme. Así, fue indudable en ese momento que la figura mítica de Lilith se calcaba en la película, cuando la mujer pide estar arriba. También adquirió sentido el hecho textual de que cuando ella sale del hotel llora y no puede explicarse por qué. "Estoy perdida”, afirma, sensación reforzada por una imagen borrosa (fuera-de-lugar), que acentúa el zoom de la cámara e interpretable como el sentimiento femenino de la (auto)expulsión del paraíso original por no poder equilibrar poderes, según el género ${ }^{3}$.

Ya para ese momento habíamos logrado confirmar, gracias a varios portales de la Red, que, justa-

3 “Y creó Dios al hombre a su imagen, a imagen de Dios lo creó; varón y mujer los creó" Génesis, 1:27. (Reina-Valera, 1960). mente, por esto, según la leyenda, Lilith se refugia fuera del paraíso y luego es reemplazada por Eva que proviene de una parte del hombre, marca de su dependencia y sometimiento frente a Adán. Esto fue lo que nos permitió construir una hipótesis de sentido, dado que fue notorio cómo la información sobre la leyenda de Adán y Eva, que atrajo la de Lilith, admitió tejer el querer-decir de la película. Esta leyenda es lo prototípico en la Biblia y en el Corán, mientras que la película de Fontayne las confrontaba con la "leyenda de Kabylie". De esta suerte, se asistía a una especie de reedición del mito de la primera pareja del mundo, que era, al tiempo, una traducción: la ella del filme se ajusta a una identidad, es Lilith; y, como Lilith, ella también sale expulsada del paraíso (interior del cuarto de fondo azul) por persistir en una posición igualitaria de querer/poder. He aquí una traducción lograda con el trabajo inferencial, esto es, con el manejo de presupuestos que 
arrojaba el texto fílmico. Al final, concluíamos que el único recurso de poder que ella tuvo fue valorar la interacción desde la periferia, desde el extremo opuesto de la fuente, que simboliza (el eterno retorno de) la vida, tal como, según el mito de Lilith, ella lo hacía lejos del paraíso, en el Mar Rojo.

Posteriormente, nos detuvimos para evaluar el ejercicio y tratar de descubrir cómo nuestro conocimiento en la acción había contribuido a ese inesperado resultado, una hipótesis de sentido con una carga altamente inferencial. No obstante, pese al trabajo delicado con las redes del tejido que conformaban el filme, algunas participantes aún temían haber sobre-interpretado o mal interpretado el texto. De suerte que, tras una nueva indagación sobre la lexía Kabylie, descubrimos que es una región de Argelia, al norte de África, cuya religión oficial es el Islam, que, como se sabe, resalta el rol femenino basado en el respeto, la obediencia y la subordinación al hombre. Por estas y otras idas y venidas contextuales, sosteníamos nuestra apreciación.

\section{Sobre la clausura de la experiencia: una lectura crítica}

Quizá lo más significativo de todo esto fue que, frente a la captura de una hipótesis sobre el querer decir del filme, las profesoras participantes del Seminario inauguraron un ejercicio lector que, sin lugar a equivocarnos, podemos llamar de lectura crítica, pues pusieron a dialogar los contenidos implícitos del filme con relatos que conocían e, incluso, habían trabajado otrora en contexto de sesiones de español funcional y literatura.

En Colombia, se habla con frecuencia (guiados por documentos institucionales) de tres niveles graduales de lectura (Pérez Abril, 1999), y se asocia la lectura crítica con la intertextualidad, esto es, la capacidad del estudiante-lector para procesar relaciones explícitas o implícitas que un texto-base mantiene con otros textos, lo cual supone un ejercicio inferencial y un stock de saberes previos o contexto cognitivo aceptable. Dicho de otra forma, la lectura crítica es la acción de reconocer la presencia de las voces de los diversos textos que se representan en el texto que se lee. Según Genette (1982), intertextualidad debe diferenciarse de paratextualidad, que concierne al contorno del texto (títulos, prefacios...); de metatextualidad, que refiere a la relación de comentario de un texto en otro; de architextualidad, que relaciona un texto con las clases a las que pertenece; y de hipertextualidad, por medio de la cual un texto (hipotexto) se incorpora a un texto anterior (hipertexto), sin que sea un comentario, bajo estrategias como la parodia, el pastiche, la transposición, etc. Pero, todas estas habilidades se asemejan puesto que, en suma, obligan un trabajo abductivo que genera un lector cuando desea construir una intención de los textos, por lo que:

Es imposible de aprender si los acervos textuales del lector son muy limitados [...] La diversidad textual - periódicos, revistas, antologías de poesía, cuento, ensayo, crónica y divulgación científica- y la formación pedagógica de los docentes orientada hacia la intersección entre los textos puede garantizar la formación del lector crítico, que es en sí la formación de un ciudadano con criterio. (Jurado, 2014, p. 12)

Es así como apareció en escena un paratexto, el relato de Juan José Arreola llamado "Eva”, por lo que nos fuimos a revisar placenteramente la microhistoria. Se trata de un hombre y una mujer (al comienzo sin identidad, al final "ella" es llamada "Eva") que discuten dentro de una biblioteca especializada en literatura española de los siglos XVI y XVII, esto es, la literatura pastoril que cuenta desventuras amorosas. Él trata de excusar su conducta desde el discurso científico (por ejemplo, la teoría de J. J. Bachofen) ${ }^{4}$ que lo enaltecía como parte del género masculino; ella, con un discurso más emocional, le respondía con agravios e insultos. Finalmente, ella (Eva) lo perdona, y de paso al género masculino, cuando escucha de él un discurso fabuloso o ficcional, atri-

4 Bachofen fue un sociólogo suizo que publicó en 1861 su obra $E I$ matriarcado: Una investigación sobre la ginecocracia en el mundo antiguo según su naturaleza religiosa y jurídica (1987), en la que sustenta que en las sociedades antiguas, comunidades nómadas y salvajes, gobernaba el poder femenino, cuya deidad predominante habría sido una proto-Afrodita terrena. 
buido arbitrariamente a Heinz Wölpe, que resulta ser un autor inexistente o supuesto:

En el principio solo había un sexo, evidentemente femenino, que se reproducía automáticamente. Un ser mediocre comenzó a surgir en forma esporádica, llevando una vida precaria y estéril frente a la maternidad formidable. Sin embargo, poco a poco fue apropiándose ciertos órganos esenciales. Hubo un momento en que se hizo imprescindible. La mujer se dio cuenta, demasiado tarde, de que le faltaba ya la mitad de sus elementos y tuvo necesidad de buscarlos en el hombre, que fue hombre en virtud de esa separación progresista y de ese regreso accidental a su punto de origen.

(Arreola, 1995, p. 391)

Esto nos obligó a analizar el relato, tratando de seguir la misma metodología con la que habíamos procedido frente al filme. El resultado nos dejó ver cómo, en el estado inicial, este, cualificado como un perseguidor/cazador, tenía un saber científico pero no el poder de producir efectos con él y, solo al final, con astucia y persistencia, persuade a Eva, y queda así modalizado con un poder y un saber, validado desde la mentira y la trampa. Todo esto, mientras ella, que en el estado inicial del relato representa un género históricamente ultrajado y reducido a la esclavitud, se representa al final como alguien que pierde la voluntad $y$, vulnerable al poder discursivo del hombre, queda dominada, acto que va en clara oposición al mito que él le comunica para doblegarla, y en armonía con el mito bíblico de Eva.

Efectivamente, la leyenda de Wölpe evocaba elementos del mito platónico del andrógino, pero también alertaba sobre una cierta corrección biologicista frente a la leyenda de Eva, pues la humanidad emerge de un cuerpo femenino y no de las entrañas de un hombre, como sí sucede con el mito bíblico, en el que Eva fue creada de una costilla de Adán y entregada a este por Dios para que fuera su mujer, lo que justifica el poder de Adán sobre ella. Enseguida fue clara la otra relación: la leyenda de Kabilye advertía que hay una verdadera historia de Adán y Eva, esto es, de la primera mujer del mundo, quien al comienzo tenía un poder que fue progresivamente neutralizado por el hombre hasta quedar a su merced. Así, la mujer, tanto del filme como del cuento, pasa de tener un lugar de poder $y$ dominio a un lugar de abnegación y sacrificio (he ahí la referencia a la Virgen María o Madonna de Arreola), mediado por "un arreglo" mentado por el poder discursivo masculino.

De esta suerte, se reconstruía la hipótesis originalmente lograda: el mantenimiento de la organización social donde es el hombre la autoridad se logra por medio del poder discusivo y desde un lugar determinado (una biblioteca que se especializa en obras que muestran el fracaso relacional o una cafetería donde él habla y decide por los dos). Y, para el caso del cuento de Arreola, no cualquier discurso, dado que no funcionó ni el discurso artístico (literatura), ni el científico o filosófico, sino el discurso mítico (ficcional), aquel "apenas comprobable"; que pudimos asemejar sin temores al discurso embustero que usa el hombre muchas veces para lograr sus metas frente a las mujeres. Esto se complementó con la referencia a otro brevísimo relato que refirió otra participante del curso electivo, esta vez del escritor uruguayo Eduardo Galeano y titulado "La autoridad", el cual fungió como un nuevo acto de intertextualidad:

En épocas remotas, las mujeres se sentaban en la proa de la canoa y los hombres en la popa. Eran las mujeres quienes cazaban y pescaban. Ellas salían de las aldeas y volvían cuando podían o querían. Los hombres montaban las chozas, preparaban la comida, mantenían encendidas las fogatas contra el frío, cuidaban a los hijos y curtían las pieles de abrigo.

Así era la vida entre los indios Onas y los Yaganes, en la tierra del Fuego, hasta que un día los hombres mataron a todas las mujeres y se pusieron las máscaras que las mujeres habían inventado para darles terror.

Solamente las niñas recién nacidas se salvaron del exterminio. Mientras ellas crecían, los asesinos les decían y les repetían que servir a los hombres era su destino. Ellas lo creyeron. También lo creyeron sus hijas y las hijas de sus hijas. (Galeano, 1995, p. 8) 
Aquí, nuevamente, se presenta una dicotomía de género (hombres y mujeres). Al comienzo eran las mujeres las que tenían el poder y la autonomía: se sentaban en la proa de la canoa, realizaban las actividades de supervivencia y salían de las aldeas y volvían cuando podían o querían. No obstante, en el desarrollo del relato se va mostrando cómo se invierte el poder entre los géneros, centrado en el caso de las comunidades indígenas de La Tierra del Fuego, hecho verificable históricamente, como un pueblo precolombino de cazadores-recolectores que desarrolló el nomadismo y que realizaban ceremonias secretas llamadas kloketen, en la cual los hombres adultos enseñaban a los jóvenes púberes el secreto para mantener sometidas a las mujeres (Füssel y Lizama, 1989). Es así como los hombres, a través de ceremonias/rituales con máscaras o representaciones, esto es, con el uso de la dimensión simbólica, restablecían míticamente un lugar de dominio sobre las mujeres a través de la palabra dicha desde un lugar de preferencia y repetida ritualmente.

\section{A manera de conclusión}

De esta manera, la experiencia fijada atestigua el valor de "aprender haciendo" en situaciones de baja ansiedad, en las que el profesor y los demás compañeros fungen como guías frente al trabajo que ayuda a que los demás ejerzan prácticas propedéuticas para que gradualmente pasen de lectores ingenuos a leedores, que incitan cuando la labor es correcta y alertan cuando hay errores de sobre-interpretación; esto es, cuando hay una arbitrariedad con el material sígnico-indicial. He aquí una forma de comprender la epistemología reflexiva de Schön; pero, también, de entender cómo se puede fortalecer la competencia lectora, un método, un camino, mediante el cual se logra trascender la literalidad de los relatos con una justa gimnasia de demostraciones textuales-contextuales, de consejos, de planteamientos culturales, y de crítica frente al punto de vista convergente, en relación con lo que insinúa el texto, y divergente, en la forma de asumir las hipótesis de sentido edificadas conjuntamente. Acuerdos y desacuerdos que, en suma, permiten aprender del otro, y para el otro, cuando de transposiciones didácticas se trata.

\section{Referencias}

Arreola, J. J. (1995). Obras completas. México: Fondo de Cultura Económica.

Bachofen, J. J. (1987). El matriarcado: Una investigación sobre la ginecocracia en el mundo antiguo según su naturaleza religiosa y jurídica. Madrid: Akal.

Beristáin, H. (1997). Análisis e interpretación del poema lírico. México: UNAM.

Cajiao, F. (Abril 7, 2014). Otra vez Pisa. El Tiempo. Recuperado de: http://www.eltiempo.com/opinion/ columnistas/otra-vez-pisa-francisco-cajiao-columnista-el-tiempo/13798017

Camargo, M. (2005). Maestro-investigador y ¿por qué no? En Hernández, C. A., Plata, J. y Camargo, M. Navegaciones. El magisterio y la investigación. Bogotá: Unesco-Colciencias.

Cassís, A. (2011). Donald Schön: una práctica profesional reflexiva en la universidad. Compás Empresarial, 3(5), 14-21.

Eco, U. (1981). Lector in fábula. Madrid: Lumen.

Eco, U. (1995). Interpretación y sobre-interpretación. Cambridge: University Press.

Flórez, R., Torrado, M. C., Arévalo, Í., Mesa, C., Mondrágón, S. y Pérez, C. (2005). Habilidades metalingüísticas, operaciones metacognitivas y su relación con los niveles de competencia en la lectura y la escritura: un estudio exploratorio. Forma $y$ Función, 18, 12-52.

Quinet, P. y Rausin, O., y Fonteyne, F. (1999). Une liaison pornographique., Suiza, Bélgica y Francia: Coproducción Francia-Bélgica-Luxemburgo-Suiza; Artemis Produtions / Samsa Film / Productions Lazennec / ARP Sélection / Fama Film / Canal+ / Eurimages / SF

Füssel, L., y Lizama, O. (1989). El pintoresco ceremonial de los onas. Impactos, 1.

Galeano, E. (1995). Mujeres. Madrid: Alianza.

Genette, G. (1982). Palimpsestos. Madrid: Taurus.

Graves, R. (2000). Los mitos hebreos. Madrid: Alianza editorial.

Ingarden, R. (1998). La obra de arte literaria. México: Taurus. 
Jurado, F. (2014). La lectura crítica: el diálogo entre los textos. Ruta Maestra, 8, 10-15.

Larrosa, J. (2007). Leer (y enseñar a leer) entre las lenguas. 20 fragmentos (y muchas preguntas) sobre lectura y pluralidad. En J. Larrosa, L. Fernández, H. Delgado, F. Van Der Huck, S. Castrillón y T. Oviedo , Leyendo en Babel. Lectura, educación y ciudad (pp. 24-34). Cali: Facultad de Derecho y Ciencias Sociales, Universidad ICESI.

Linares, A. (Mayo 24, 2013). Colombia enfrenta una alarmante brecha en la calidad educativa. El Tiempo. Disponible en: http://www.eltiempo.com/archivo/ documento/CMS-12822612

Mejía, M. R. (2009). La investigación como estrategia pedagógica. Bogotá: FES-Colciencias-Ondas.

Pérez Abril, M. (1998). Lineamientos curriculares de Lengua Castellana. Áreas obligatorias y fundamentales. Bogotá: Magisterio.
Pinilla, R., y Quitián, S. (2014). Balance de la producción de conocimiento en la Maestría en Pedagogía de la Lengua Materna. En É. García-Dussán (Comp.), Discursividad y educación. Experiencias investigativas sobre lengua materna, identidad social y cultura escolar. Bogotá: Editorial UD.

Santa Biblia. (1960). Sociedades Bíblicas en América Latina

Sarland, C. (2003). La lectura en los jóvenes: cultura y respuesta. México: Fondo de Cultura Económica.

Schön, D. (1996). La crisis del conocimiento profesional y la búsqueda de una epistemología de la práctica. En M. Pakman (Comp.), Construcciones de la experiencia humana [Vol. 1]. Barcelona: Gedisa.

Schön, D. (1998). El profesional reflexivo. Cómo piensan los profesionales cuando actúan. Barcelona: Paidós. 